\title{
A Novel Small-Molecule Inhibitor Displays Its Therapeutic Potency Through Mitochondria- Mediated Apoptosis And Autophagy In Melanoma
}

Jun Bai

Southwest Medical University

Hailan Wang

Southwest Medical University

Changzhen Sun

Affiliated Traditional Chinese Medicine Hospital, Southwest Medical University

Jianv Wang

The Affiliated Hospital of Southwest Medical University

Li Liu

The Affiliated Hospital of Southwest Medical University

Qingbi Zhang ( $\sim$ qingbizhang@126.com )

Southwest Medical University

\section{Research Article}

Keywords: small-molecule inhibitor, melanoma, mitochondrial apoptosis, autophagy, metastasis

Posted Date: December 30th, 2021

DOI: https://doi.org/10.21203/rs.3.rs-1172352/v1

License: () (1) This work is licensed under a Creative Commons Attribution 4.0 International License.

Read Full License 


\section{Abstract}

Melanoma is the most aggressive skin cancer with high mortality. It is vital to develop novel low toxicity drugs with anti-proliferation activity and metastasis suppressive activity in melanoma. Here, we reported a novel anti-tumor drug SCZ0148, and then investigated its inhibition effect on melanoma. The anticancer efficacy of SCZ0148 was confirmed by using cytotoxicity test, colony formation assay, woundhealing assay, cell apoptosis detection, mitochondrial potential assay, reactive oxygen species (ROS) production and western-blot analysis. The cytotoxicity test showed that SCZ0148 inhibited melanoma cell lines proliferation in a dose- and time-dependent manner without obvious toxicity and side effects on normal cells. The results of the colony formation assay were in agreement with the cytotoxicity test. In addition, SCZ0148 induced melanoma cell apoptosis and promoted cell destructive autophagy through the ROS-mediated mitochondrial apoptosis pathway. Notably, SCZ0148 significantly inhibited the migration of melanoma cells through the matrix metalloprotein 9 (MMP-9) mediated pathway. In conclusion, these findings suggest that SCZ0148 may be a potential therapeutic drug to inhibit the proliferation and metastasis of melanoma.

\section{Introduction}

Melanoma, which is known as malignant melanoma, is the most aggressive skin cancer with high mortality[1]. The incidence of melanoma is increasing at an annual rate of 2-7\% worldwide[2]. Melanoma accounts for $80 \%$ of mortality of all skin cancer[3]. One of the main causes of melanoma death is its rapid metastasis. The 5-year survival rate of patients with metastatic melanoma varies from $5-19 \%[4,5]$. Some of the drugs currently in place to treat melanoma, such as BRAF V600E inhibitors, interferon $a-2 b /$ interleukin-2, ipilimumab, pembrolizumab/ nivolumab, can improve patient survival to a certain degree[6, 7]. However, side effects, low reaction rates and drug resistance are the main limitations of these drugs in the treatment of melanoma[6,7]. Therefore, it is vital to develop novel low toxicity drugs with anti-melanoma activity and metastasis reduction.

Most anticancer drugs treat malignant cells by inducing cell death[8-10]. There are various ways of cancer cell death, such as apoptosis, autophagy or necrosis. Apoptosis is a programmed cell death, which is identified by the unique morphological characteristics of cells, such as nuclear chromatin condensation and nuclear fragmentation[11]. The two main pathways of apoptosis are in vitro pathway and intrinsic pathway, also known as the death receptor pathway and mitochondrial pathway[12]. Mitochondria are highly dynamic organelles, and their morphology is an important factor that determines the function of mitochondria and the ultimate fate of cells[13]. Mitochondrial destruction is a feature of programmed cell death. In the process of apoptosis, reactive oxygen species (ROS) are free radicals produced by external stimulation, which cause stress to mitochondria and lead to mitochondrial membrane potential $(\Delta \psi \mathrm{m})$ loss and disturbance of protein markers[14, 15]. Mitochondria regulates the inherent apoptotic pathway regulated by Bcl-2 family proteins, then activate the caspase-cascade to form apoptotic bodies, and eventually enter apoptosis after PARP protein cleaved, resulting in cell death[16].In addition, autophagy is a lysosomal catabolic process, which has the dual functions of cell survival and 
cell death. Under physiological or moderate stress, autophagy will be activated to protect cells, but severe stimulation (such as antitumor drugs) will lead to redundant and damaged mitochondrial autophagy, leading to bioenergy failure and eventually cell death $[17,18]$. Some studies have shown that autophagy and apoptosis form a cross-correlation responsible for maintaining intracellular homeostasis, and the inactivation or instability of these pathways play a key role in the pathogenesis of cancer[19, 20]. In summary, promoting apoptosis and destructive autophagy through drugs are effective targets for the inhibition of cancer cells.

Given the high metastasis rate and high fatality rate of melanoma, we synthesized a new anti-tumor small molecule SCZ0148 and investigated its anti-cancer effect and molecular mechanisms in melanoma cells. Our data provide evidence that SCZ0148 inhibits melanoma cell proliferation by activating reactive oxygen species (ROS) and reducing mitochondrial membrane potential $(\Delta \psi \mathrm{m})$, thereby regulating the mitochondrial apoptosis pathway and inducing cell apoptosis. In addition, the effect of SCZ0148 on autophagy was explored. We also found that SCZ0148 could inhibit the migration of melanoma cells. These data together suggest that SCZ0148 could be a potential novel drug for the treatment of melanoma.

\section{Materials And Methods}

\section{Reagents and instruments}

2,3,3-trimethylindolenine, 6-bromohexanoic acid, 1,2-dichlorobenzene and 9-anthraldehyde were purchased from Shanghai Titan Scientific Co., Ltd. (Shanghai, China). Sodium acetate, dichloromethane, methanol, and ethanol were purchased from Runze Bentu Reagent Co., Ltd. (Chengdu, China). The GFPLC3 plasmid was gifted from Dr. Jianguo Feng (Southwest Medical University, Luzhou, China). 3-(4,5dimethyl-2-thiazolyl)-2,5-diphenyltetrazolium bromide (MTT) and Hoechst 33342 dye were purchased from Shanghai Yuan Ye Bio-Technology Co., Ltd (Shanghai, China). Annexin V-FITC/PI cell apoptosis detection reagent was obtained from Biosharp Biotechnology (China). All the experimental water was secondary distilled water. Unless otherwise stated, all solvents and chemicals are reagent grade and no further purification is required for use.

Mass spectrometry analysis was performed using Thermo Q Exactive mass spectrometer. Nikon Ts2R-FL fluorescence microscope was used for captured cell fluorescence image. The absorbance was measured using a Spectra MAXM5 microplate spectrophotometer (Molecular Devices). Flow cytometry (FCM) was performed using BD FACSVerse (USA).

\section{Synthesis of compound SCZ0148}

SCZ0148 can follow the synthesis route described in scheme 1. 2,3,3-trimethylindolenine (15.9 g, 100 $\mathrm{mM}), 6$-bromohexanoic acid $(19.5 \mathrm{~g}, 100 \mathrm{mM})$, and 1,2-dichlorobenzene $(30 \mathrm{~mL})$ were added to the 100 $\mathrm{mL}$ round bottom flask, allowed to react $10 \mathrm{~h}$ at $110^{\circ} \mathrm{C}$, and then remove the oil bath so that it slows down to room temperature to obtain a system containing solid precipitation. We filled the liquid with a 
Buchner funnel, washed it three times with isopropyl alcohol, to obtain a dark ash red solid, and the oil pump was evacuated to the Intermediate. The Intermediates $(1.42 \mathrm{~g}, 4 \mathrm{mM})$, 9-anthraldehyde $(0.82 \mathrm{~g}, 4$ $\mathrm{mM})$, sodium acetate $(0.33 \mathrm{~g}, 4 \mathrm{mM})$, and ethanol $(20 \mathrm{~mL})$ were added to $50 \mathrm{~mL}$ of the round bottom flask, and the reaction was stirred at $70^{\circ} \mathrm{C}$ for $2 \mathrm{~h}$ to give a dark red solution system. After the solvent was removed by rotary evaporation, the target compound (SCZ0148) was collected by column using a dichloromethane/methanol solvent system.

The target product was obtained by rotating evaporation, and then we characterized the target product with an MS, the characterization is as follows (Fig. S1). The theoretical molecular weight of SCZ0148 is 462.2428 , and the mass spectrum was obtained as 462.2399 . This proves that the product we synthesized is correct.

\section{Cell lines and cell culture}

A375 (human malignant melanoma cell lines), B16 (mouse melanoma cell lines), and HEK 293 T (human embryonic kidney cell lines) were purchased from the American Type Culture Collection (ATCC, Rockville, MD, USA). Cells were cultured in Dulbecco's Modified Eagle's Medium (DMEM) media supplemented with $10 \%$ fetal bovine serum (FBS; Gibco, Auckland, N.Z) and 1\% antibiotic-antimycotic solution. All cell lines were maintained in a humidified atmosphere at $37^{\circ} \mathrm{C}$ and $5 \%$ humidified $\mathrm{CO}_{2}$ atmosphere.

\section{Cell viability assay}

The cell viability was detected by MTT assay. A375, B16 and 293T cells which grew at log-phase growth were inoculated in 96-well cell culture plates ( $1 \sim 5$ I $10^{3}$ cells per well), separately. After the cells incubated overnight, cells were exposed to various concentrations of $\operatorname{SCZ0148}(20,10,5,2.5,1.25,0.625 \mu \mathrm{M})$ for different times $(24,48$ and $72 \mathrm{~h})$. Then, $20 \mu \mathrm{L}$ MTT $(5 \mathrm{mg} / \mathrm{mL})$ was added to each well and cells were incubated at $37{ }^{\circ} \mathrm{C}$ and $5 \% \mathrm{CO}_{2}$ for $2-4 \mathrm{~h}$. Finally, the medium was removed, and $100 \mu \mathrm{L}$ DMSO was resuspended for $10 \mathrm{~min}$. Spectrophotometric absorbance at $570 \mathrm{~nm}$ was recorded by enzyme labeling instrument, and the cell viability was calculated by the following equation: Activity $(\%)=($ average absorbance value of the experimental group/average absorbance value of the control group) * $100 \%$. Each experiment was performed at least 3 times.

\section{Colony formation assay}

Briefly, the A375ロB16 cells (200-400 cells per well) were seeded into a 6-well plate and treated with various concentrations of SCZ0148 $(2.5,1.25,0.63,0.31 \mu \mathrm{M})$, after approximately $24 \mathrm{~h}$ of incubation. Next, the cells were incubated for another 10 days, and the medium was changed once every three days. Finally, the cells were stained with methanol and dyed with $0.5 \%$ crystal violet (Beyotime Biotechnology, Beijing, China). The colonies ( $>50$ cells) were recorded by manual counting.

\section{Wound-healing assay}


The A375, B16 cells were allowed to grow into full confluence in 6-well plates and then wounded by scratching with pipette tips and further washed with phosphate buffer solution (PBS) twice. After washed with phosphate buffer solution (PBS), the cells were incubated with different concentrations of SCZ0148 $(1.25,2.5,5,10 \mu \mathrm{M})$ for $12 \mathrm{~h}$ at $37^{\circ} \mathrm{C}$ and $5 \% \mathrm{CO}_{2}$. Random photos were taken under the microscope to observe the cell migration ability. Independent experiments were repeated three times.

\section{Transwell migration assay}

The migration of B16 cells was evaluated with Transwell chambers ( $8 \mu \mathrm{m}$ pore; labselect inc.). Cells in $200 \mu \mathrm{L}$ serum-free medium with different concentrations of SCZ0148 $(1.25,5 \mu \mathrm{M})$ were added to the upper chamber at a density of $51105 / \mathrm{mL}$, and $500 \mu \mathrm{L}$ medium containing $20 \%$ FBS was placed in the lower chamber. After treatment with SCZ0148 for $24 \mathrm{~h}$, the migrated cells were fixed with methanol and stained with crystal violet. Finally, cells were taken by a light microscope (Nikon Corporation, Japan) and counted by eye.

\section{Morphological analysis by Hoechst staining}

In brief, A375 and B16 cells ( 1 I $10^{5}$ cells per well) were plated into 6-well plates overnight. After treated with various concentrations of SCZ0148 $(1.25,2.5,5,10 \mu \mathrm{M})$ for $12 \mathrm{~h}$, the cells were washed with PBS and stained with Hoechst 33342 solution $(2 \mu \mathrm{g} / \mathrm{mL})$. Lastly, the morphology of nuclear was observed by a fluorescence microscope.

\section{Annexin V-FITC cell apoptosis detection}

The A375 and B16 cells ( 2 í $10^{5}$ cells/well) were seeded in 6-well plates for $24 \mathrm{~h}$. After $24 \mathrm{~h}$ of treatment with gradient concentrations of SCZ0148 $(1.25,2.5,5,10 \mu \mathrm{M})$, the cells were collected, washed with cold PBS and stained with Annexin V-FITC/PI detection kit as the manufacturer instructed. Flow cytometry (FCM) was used to analyze the apoptosis induced by SCZ0148.

\section{JC-1 mitochondrial membrane potential assay}

The mitochondrial membrane potential assay was performed by the $\mathrm{JC}-1$ staining kit as instructed by the manufacturer. Briefly, cells were incubated with JC-1 fluorescent dye $(10 \mu \mathrm{g} / \mathrm{mL})$ at $37^{\circ} \mathrm{C}$ in the dark for 20 min after SCZ0148 exposure for $24 \mathrm{~h}$. Then, the cells were washed two times with PBS solution. The cells marked with JC-1 were detected by a fluorescence microscope. A decrease in the ratio of red to green was employed to indicate the $\Delta \psi m$ collapse.

\section{Measurement of intracellular ROS}

A375 and B16 cells at $80 \%$ cell confluence were incubated in the different concentrations of SCZ0148 $(1.25,2.5,5,10 \mu \mathrm{M})$ for $1 \mathrm{~h}$. After the incubation, the cells culture medium was replaced with a fresh medium involving $6.7 \mu \mathrm{M}$ 2',7'-dihydrofluorescein-diacetate $\left(\mathrm{DCFH}_{2}-\mathrm{DA}\right)$ and incubated for $40 \mathrm{~min}$ at 37 ${ }^{\circ} \mathrm{C}$. The level of intracellular ROS is directly proportional to the accumulation of intracellular 
dichlorofluorescein (DCF) caused by the oxidation of $\mathrm{DCFH}_{2}$-DA. The fluorescence microscope was employed to observe and photograph. Fluorescence intensity was measured by Image $\mathrm{J}$ software.

\section{Western blotting analysis}

The A375 and B16 cells were collected and lysed with ice-cold RIPA buffer containing a protease inhibitor cocktail. The concentration of protein was measured by the bicinchoninic acid (BCA) (Beyotime, China) method, then heating it at $95^{\circ} \mathrm{C}$ for $10 \mathrm{~min}$ after being mixed with loading buffer. Equal quantities of (20 $\mu \mathrm{g}$ ) of solubilized protein samples were separated by $10-12 \%$ polyacrylamide gradient SDS-PAGE gels. After separation, the proteins samples were transferred to a polyvinylidene difluoride (PVDF) membrane, following the membranes incubated with $5 \%$ blotto ( $5 \%$ nonfat dry milk, $1 \%$ Tween-20 in PBS) for $1.5 \mathrm{~h}$ at room temperature. After blocking, membranes were incubated with different primary antibodies at $4{ }^{\circ} \mathrm{C}$ for $12 \mathrm{~h}$. On the following day, membranes were probed with horseradish peroxidase (HRP) for $1.5 \mathrm{~h}$. Finally, the blots were visualized through the ECL system (Vilber, Fusion solo 4, France). Protein densitometric analysis was performed using the Image $J$ software. Data were depicted as a fold difference over untreated control. GAPDH was performed as an internal control. Antibody information is shown in Table S1.

\section{Analysis of GFP-LC3 aggregates}

Inoculated A375 and B16 cells into a 24-well plate with a cell density of $40 \%-60 \%$, and adhered overnight. The GFP-LC3 plasmid was transfected into A375 and B16 cells according to the manufacturer's protocol of lipfiter transfection reagent (Hanbio, China). After a $12 \mathrm{~h}$ transfection, the cells were treated with various concentrations of SCZ0148 $(1.25,2.5,5,10 \mu \mathrm{M})$ for $24 \mathrm{~h}$, fluorescence microscope was employed by observing the GFP-LC3 aggregates.

\section{Statistical analysis}

All the data were presented as mean \pm standard deviation and analyzed with SPSS 17.0 software. The differences between the control and treatment groups were calculated by $t$-test of two independent samples. $P<0.05$ suggests that the difference is statistically significant.

\section{Results}

\section{SCZ0148 inhibits melanoma cells proliferation}

The MTT method was employed to determine the antitumor activity of SCZ0148. Briefly, A375 and B16 cells were treated with gradient concentrations of SCZ0148, and the cells were maintained in the range of $0.625 \sim 20 \mu \mathrm{M}$ for $24 \mathrm{~h}, 48 \mathrm{~h}$ and $72 \mathrm{~h}$, respectively. As shown in Fig. $1 \mathrm{~A}$ and $\mathrm{B}$, the cytotoxicity of SCZ0148 to A375 and B16 cells both showed a dose- and time- dependence manner and the $\mathrm{IC}_{50}$ values of $\mathrm{A} 375$ and $\mathrm{B} 16$ for $72 \mathrm{~h}$ were $4.40 \pm 0.44 \mu \mathrm{M}, 3.32 \pm 0.58 \mu \mathrm{M}$, respectively. However, it had no obvious cytotoxicity to $293 \mathrm{~T}$ cells, even if the concentration reaches $20 \mu \mathrm{M}$ (Fig. 1C). To further evaluate whether 
SCZ0148 could inhibit the proliferation of melanoma cells, the colony formation assay was performed on melanoma cells after treated with SCZ0148. As shown in fig. 1D, the clone formation of A375 and B16 cells were significantly reduced in a dose-dependent manner after treatment of SCZ0148. Moreover, compared with the control group, the size of colony formation of the SCZ0148 treatment group was significantly smaller. These results indicated that SCZ0148 could selectively inhibit melanoma cells proliferation.

\section{SCZ0148 induces melanoma cells apoptosis via caspases activation}

We explored the effect of SCZ0148 on inducing apoptosis of melanoma cells. Firstly, Hoechst33342 staining assay was conducted to investigate the cells apoptosis by SCZ0148. As displayed in Fig. 2A, compared with the control group, bright-blue fluorescent-condensed nuclei and nuclear fragmentation were observed in the group treated with SCZ0148, and the number of nuclei and nuclear fragmentation increased in a concentration-dependent manner. To further confirm the apoptosis of A375 and B16 cells induced by SCZ0148, we conducted Annexin V-FITC/PI double-labeling method and flow cytometry to detect the apoptosis rate of A375 and B16 cells. As shown in Fig. 2B, SCZ0148 induced apoptosis of

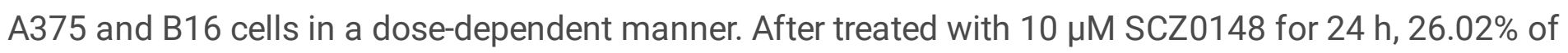
late apoptotic A375 cells and $42.30 \%$ of late apoptotic B16 cells were measured. Meanwhile, the late apoptotic rate in the control group was only $4.35 \%$ and $1.15 \%$ respectively. Thus, SCZ0148 displayed a potent potential to induce apoptosis in melanoma cells. To further explore how SCZ0148 activates apoptosis, we detected the expression of apoptosis-related proteins. Consistent with the results of flow cytometry, Western blot detection demonstrated that SCZ0148 treatment also increased the expression of Bax, cleaved caspase-9, and cleaved caspase-3 and the cleavage of PARP in A375 and B16 cells (Fig. 2C, D). These results suggest that SCZ0148 may induce apoptosis of melanoma cells by activating the caspases pathway, which is related to the apoptotic pathway of mitochondria.

\section{SCZ0148 induces mitochondria-mediated apoptosis in melanoma cells}

The decrease of mitochondrial membrane potential $(\Delta \psi \mathrm{m})$ is an important factor affecting apoptosis[21]. To verify the relationship between apoptosis induced by SCZ0148 and the pathway of mitochondrial apoptosis, we used JC-1 to evaluate the changes of $\Delta \psi \mathrm{m}$. As shown in Fig. 3A, B, after SCZ0148 treatment, the $\Delta \psi \mathrm{m}$ in $\mathrm{A} 375$ and B16 cells decreased significantly, and the fluorescence transferred from red to green in a dose-dependent manner. Then, the level of reactive oxygen species was observed by fluorescence microscope with DCFH-DA as the indicator. Compared with the control group, the level of ROS in the cells treated with SCZ0148 was significantly higher than that in the control group (Fig. 3C). SCZ0148 treatment led to the accumulation of intracellular ROS. These results suggest that SCZ0148induced apoptosis may be involved in the mitochondrial-mediated apoptosis pathway.

\section{SCZ0148 induces autophagy in melanoma cells}

In addition to the apoptotic pathway, disorders of autophagy can also aggravate tumorigenesis, infectious diseases and neurodegenerative diseases[22]. In recent years, autophagy has been 
emphasized as a new therapeutic target, which has a wide range of beneficial effects on cancer[23-25]. Thus, we evaluated the effect of SCZ0148 on the autophagy of melanoma cells by observing the formation of autophagosomes and the main protein changes of autophagy. The increase of autophagosome formation in A375 and B16 cells treated with SCZ0148 for $24 \mathrm{~h}$ was confirmed by the fluorescence localization of autophagy marker GFP-LC3 (Fig. 4A). The transformation of microtubuleassociated protein 1 light chain 3 (LC3-I) to LC3-II represents the occurrence of autophagy[26]. The expression of LC3-I and LC3-II proteins were detected by Western blot. Fig. 4B showed that SCZ0148 significantly increased the expression of LC3-II in a dose-dependent manner. In summary, these results confirm that SCZ0148 increases the autophagy level of melanoma cells.

\section{SCZ0148 impairs the migration of melanoma cells in vitro}

The anti-metastasis effect of SCZ0148 was assessed by cell wound-healing, transwell migration and western blot assays. As demonstrated in Fig. 5A and B, SCZ0148 inhibited the migration of A375 and B16 cell lines in a dose-dependent manner. Then, we investigated whether matrix metalloprotein 9 (MMP-9) is closely associated with cell migration is involved in SCZ0148-associated migration through western-blot assay. As displayed in Fig. 5C, MMP-9 showed an obvious decrease after the treatment of SCZ0148. These results reveal that SCZ0148 is effective in inhibiting the migration of melanoma cells.

\section{Discussion}

Melanoma is the deadliest form of skin cancer because of its high metastatic potential[27]. Melanoma greatly affects the quality of life and brings huge medical costs for individuals, families and countries. Unfortunately, there is no effective treatment to control melanoma and its metastasis. Therefore, it is urgent to invent a new drug for the treatment of melanoma. In this study, we synthesized a new antineoplastic drug, SCZ0148, and evaluated its anti-melanoma effect in vitro and discussed its mechanisms. The results of MTT and colony formation showed that SCZ0148 significantly inhibited the viability and proliferation of melanoma cells in a time and dose-dependent manner. And SCZ0148 had no toxicity to non-tumor cell lines. Then, we explored the role of SCZ0148 in cell death and the overall mechanism of their anti-proliferation effects is shown in Fig. 6. In conclusion, SCZ0148 has a good antiproliferation effect on melanoma cells.

Apoptosis is a way of programmed cell death, which can be used as a potential target for the prevention and treatment of malignant tumor cell proliferation[28,29]. The activation of caspases related proteins leads to apoptosis cascade[30]. Apoptosis includes the death receptor-mediated apoptosis pathway and mitochondrial-regulated apoptosis pathway. Mitochondria play an important role in endogenous apoptosis by changing mitochondrial transmembrane potential. Bcl-2 family proteins such as proapoptotic protein Bax may be involved in the endogenous apoptosis pathway[31, 32]. Moreover, the proapoptotic protein Bax can insert the external granule membrane, increase the mitochondrial permeability and promote the decrease of $\Delta \psi \mathrm{m}$ and cytochrome $\mathrm{c}$ release[33]. With the release of cytochrome $\mathrm{c}$, Caspases 9 and Caspase 3, which play a key role in the mitochondrial apoptosis pathway, are activated 
in turn, and PARP is cleaved, leading to the final apoptosis[34,35]. Our results showed that the treatment of SCZ0148 resulted in the decrease of mitochondrial membrane potential, the increase of Bax protein level, the cleavage of Caspases9, 3 and PARP, and the increase of late apoptotic cells in melanoma cells. All these suggest that SCZ0148 promotes apoptosis through the mitochondrial apoptosis pathway in a time-and dose-dependent manner. ROS production is representative markers of apoptosis progression[36]. In the study of other anti-melanoma active substances, it has been found that the production of ROS is related to the activation of caspase apoptosis pathway[37, 38]. Thus, the accumulation of ROS induced by SCZ0148 may also indicate the mitochondrial dysfunction related to apoptosis in melanoma cells. In summary, SCZ0148 induces ROS accumulation, leads to mitochondrial dysfunction, activates the caspases signal pathway, and eventually leads to apoptosis.

Autophagy is a catabolic pathway that can degrade and recover defective organelles or longevity proteins and help to maintain the stability of the intracellular environment. Therefore, autophagy may be a promising target for tumor therapy[39, 40]. Autophagy is a double-edged sword, which has the mechanism of cell survival or death for therapeutic drugs. The significant increase of GFP-LC3 aggregates is a landmark event of autophagy, which is related to the significant accumulation of LC3-II in cells. We found that SCZ0148 treatment upregulated the transformation of LC3-I to LC3-II (membranebound) and increased the distribution of GFP-LC3 spots in A375 and B16 cells. This explains why SCZ0148 recruits autophagosomes by increasing LC3-II protein and inducing autophagy in melanoma cells. SCZ0148 significantly increased the number of autophagosomes in melanoma cells and promoted destructive autophagy. Similar to other antineoplastic substances[10,37], our study finds that SCZ0148 plays anti-tumor effects by inducing autophagy.

Melanoma is a cancer characterized by high metastasis[41]. Moreover, the poor therapeutic effect of melanoma is involved in the high metastatic potential of melanoma cells[42, 43]. Therefore, the cell wound healing and transwell migration assay was performed to evaluate the anti-metastasis effect of SCZ0148. MMP-9 is a key regulator of cell migration[44]. Consequently, Western Blot assay was employed to detect the protein expression of MMP-9. After treated with SCZ0148, cell migration was inhibited and the protein expression of MMP-9 was down-regulated. These results confirm that SCZ0148 has an effective anti-melanoma cell migration effect.

\section{Conclusions}

In this study, compound SCZ0148 was synthesized and its antitumor effect on melanoma cells was evaluated. SCZ0148 displayed an anti-proliferation effect on melanoma cells in a time- and dosedependent manner. Moreover, further research results suggest that SCZ0148 may induce cell apoptosis through the ROS-mediated mitochondrial apoptosis pathway and promote cell destructive autophagy to produce an anti-tumor effect. In addition, SCZ0148 significantly inhibited the migration of melanoma cells through the MMP-9-mediated pathway. Therefore, these results reveal that SCZ0148 may be a novel potential therapeutic drug to inhibit the proliferation and metastasis of melanoma. 


\section{Declarations}

Author Declarations

Ethics approval and consent to participate This article does not contain any studies with human participants or animals performed by any of the authors.

Consent for publication Not applicable.

Availability of data and materials All data and results contained in this paper are available upon request.

Competing interests The authors declare that there are no competing interests.

Funding This work was supported by Luzhou Municipal People's Government-Southwest Medical University Science and Technology Strategic Cooperation Project (2017LZXNYD-J24, 2018LZXNYDZK20); Fund project of Southwest Medical University (2020ZRQNB002).

Authors' contributions Jun Bai: Conceptualization, Methodology, Supervision. Hailan Wang: Data curation, Writing- Original draft preparation. Changzhen Sun: Chemical synthesis, Formal analysis. Jianv Wang: Visualization, Investigation. Li Liu: Writing- Reviewing and Editing. Qingbi Zhang: Supervision, Funding acquisition.

Acknowledgements We are grateful to Dr. F. Jianguo who gifted us the GFP-LC3 plasmid.

\section{Compliance with Ethical Standards}

Disclosure of potential conflicts of interest The authors have no relevant financial or non-financial interests to disclose.

Research involving Human Participants and/or Animals Not applicable.

Informed consent Not applicable.

\section{References}

1. Bray F, Ferlay J, Soerjomataram I, Siegel RL, Torre LA, Jemal A (2018) Global cancer statistics 2018: GLOBOCAN estimates of incidence and mortality worldwide for 36 cancers in 185 countries. CA Cancer J Clin 68:394-424. 10.3322/caac.21492

2. Gladfelter P, Darwish NHE, Mousa SA (2017) Current status and future direction in the management of malignant melanoma. Melanoma Res 27:403-410. 10.1097/cmr.0000000000000379

3. Zhao Z, Liao N (2021) Bergamottin Induces DNA Damage and Inhibits Malignant Progression in Melanoma by Modulating miR-145/Cyclin D1 Axis. Onco Targets Ther 14:3769-3781. $10.2147 /$ ott.S275322 
4. Bandarchi B, Jabbari CA, Vedadi A, Navab R (2013) Molecular biology of normal melanocytes and melanoma cells. J Clin Pathol 66:644-648. 10.1136/jclinpath-2013-201471

5. Maverakis E, Cornelius LA, Bowen GM, Phan T, Patel FB, Fitzmaurice S, He Y, Burrall B, Duong C, Kloxin AM, Sultani H, Wilken R, Martinez SR, Patel F (2015) Metastatic melanoma - a review of current and future treatment options. Acta Derm Venereol 95:516-524. 10.2340/00015555-2035

6. Zhu Z, Liu W, Gotlieb V (2016) The rapidly evolving therapies for advanced melanoma--Towards immunotherapy, molecular targeted therapy, and beyond. Crit Rev Oncol Hematol 99:91-99. 10.1016/j.critrevonc.2015.12.002

7. Millet A, Martin AR, Ronco C, Rocchi S, Benhida R (2017) Metastatic Melanoma: Insights Into the Evolution of the Treatments and Future Challenges. Med Res Rev 37:98-148. 10.1002/med.21404

8. Su WC, Lin YF, Yu XP, Wang YX, Lin XD, Su QZ, Shen DY, Chen QX (2017) Mitochondria-Associated Apoptosis in Human Melanoma Cells Induced by Cardanol Monoene from Cashew Nut Shell Liquid. J Agric Food Chem 65:5620-5631. 10.1021/acs.jafc.7b01381

9. Lei Q, Xiong L, Xia Y, Feng Z, Gao T, Wei W, Song X, Ye T, Wang N, Peng C, Li Z, Liu Z, Yu L (2018) YLT11, a novel PLK4 inhibitor, inhibits human breast cancer growth via inducing maladjusted centriole duplication and mitotic defect. Cell Death Dis 9:1066. 10.1038/s41419-018-1071-2

10. Zhao M, Gu L, Li Y, Chen S, You J, Fan L, Wang Y, Zhao L (2019) Chitooligosaccharides display antitumor effects against human cervical cancer cells via the apoptotic and autophagic pathways. Carbohydr Polym 224:115171. 10.1016/j.carbpol.2019.115171

11. Lockshin RA, Zakeri Z (2004) Apoptosis, autophagy, and more. Int J Biochem Cell Biol 36:24052419. 10.1016/j.biocel.2004.04.011

12. Sheridan JP, Marsters SA, Pitti RM, Gurney A, Skubatch M, Baldwin D, Ramakrishnan L, Gray CL, Baker K, Wood WI, Goddard AD, Godowski P, Ashkenazi A (1997) Control of TRAIL-induced apoptosis by a family of signaling and decoy receptors. Science 277:818-821. 10.1126/science.277.5327.818

13. Wu NN, Tian H, Chen P, Wang D, Ren J, Zhang Y (2019) Physical Exercise and Selective Autophagy: Benefit and Risk on Cardiovascular Health, Cells 8. 10.3390/cells8111436

14. Elmore S (2007) Apoptosis: a review of programmed cell death. Toxicol Pathol 35:495-516. 10.1080/01926230701320337

15. Khan I, Kang SC (2017) Apoptotic Activity of Lactobacillus plantarum DGK-17-Fermented Soybean Seed Extract in Human Colon Cancer Cells via ROS-JNK Signaling Pathway. J Food Sci 82:14751483. $10.1111 / 1750-3841.13732$

16. Susin SA, Lorenzo HK, Zamzami N, Marzo I, Snow BE, Brothers GM, Mangion J, Jacotot E, Costantini P, Loeffler M, Larochette N, Goodlett DR, Aebersold R, Siderovski DP, Penninger JM, Kroemer G (1999) Molecular characterization of mitochondrial apoptosis-inducing factor. Nature 397:441-446. $10.1038 / 17135$

17. Lu J, Qian HY, Liu LJ, Zhou BC, Xiao Y, Mao JN, An GY, Rui MZ, Wang T, Zhu CL (2014) Mild hypothermia alleviates excessive autophagy and mitophagy in a rat model of asphyxial cardiac arrest. Neurol Sci 35:1691-1699. 10.1007/s10072-014-1813-6 
18. Liang X, Wang S, Wang L, Ceylan AF, Ren J, Zhang Y (2020) Mitophagy inhibitor liensinine suppresses doxorubicin-induced cardiotoxicity through inhibition of Drp1-mediated maladaptive mitochondrial fission. Pharmacol Res 157:104846. 10.1016/j.phrs.2020.104846

19. Long JS, Ryan KM (2012) New frontiers in promoting tumour cell death: targeting apoptosis, necroptosis and autophagy. Oncogene 31:5045-5060. 10.1038/onc.2012.7

20. Su Z, Yang Z, Xu Y, Chen Y, Yu Q (2015) Apoptosis, autophagy, necroptosis, and cancer metastasis. Mol Cancer 14:48. 10.1186/s12943-015-0321-5

21. Cosentino K, García-Sáez AJ (2014) Mitochondrial alterations in apoptosis. Chem Phys Lipids 181:62-75. 10.1016/j.chemphyslip.2014.04.001

22. Fu Y, Hong L, Xu J, Zhong G, Gu Q, Gu Q, Guan Y, Zheng X, Dai Q, Luo X, Liu C, Huang Z, Yin XM, Liu P, Li M (2019) Discovery of a small molecule targeting autophagy via ATG4B inhibition and cell death of colorectal cancer cells in vitro and in vivo. Autophagy 15:295-311. $10.1080 / 15548627.2018 .1517073$

23. Choi AM, Ryter SW, Levine B (2013) Autophagy in human health and disease. N Engl J Med 368:651-662. 10.1056/NEJMra1205406

24. Levine B, Packer M, Codogno P (2015) Development of autophagy inducers in clinical medicine. J Clin Invest 125:14-24. 10.1172/jci73938

25. Galluzzi L, Bravo-San Pedro JM, Levine B, Green DR, Kroemer G (2017) Pharmacological modulation of autophagy: therapeutic potential and persisting obstacles. Nat Rev Drug Discov 16:487-511. $10.1038 /$ nrd. 2017.22

26. Tanida I, Minematsu-lkeguchi N, Ueno T, Kominami E (2005) Lysosomal turnover, but not a cellular level, of endogenous LC3 is a marker for autophagy, Autophagy 1. 84-91. 10.4161/auto.1.2.1697

27. Huang F, Santinon F, Flores González RE, Del SV, Rincón (2021) Melanoma Plasticity: Promoter of Metastasis and Resistance to Therapy, Front Oncol 11 756001. 10.3389/fonc.2021.756001

28. Wong RS (2011) Apoptosis in cancer: from pathogenesis to treatment. J Exp Clin Cancer Res 30:87. 10.1186/1756-9966-30-87

29. Guicciardi ME, Gores GJ (2009) Life and death by death receptors. Faseb j 23:1625-1637. 10.1096/fj.08-111005

30. Tower J (2015) Programmed cell death in aging. Ageing Res Rev 23:90-100. 10.1016/j.arr.2015.04.002

31. Chaudhary AK, Yadav N, Bhat TA, O'Malley J, Kumar S, Chandra D (2016) A potential role of X-linked inhibitor of apoptosis protein in mitochondrial membrane permeabilization and its implication in cancer therapy. Drug Discov Today 21:38-47. 10.1016/j.drudis.2015.07.014

32. Warren CFA, Wong-Brown MW, Bowden NA (2019) BCL-2 family isoforms in apoptosis and cancer. Cell Death Dis 10:177. 10.1038/s41419-019-1407-6

33. Kureel J, John AA, Raghuvanshi A, Awasthi P, Goel A, Singh D (2016) Identification of GRP78 as a molecular target of medicarpin in osteoblast cells by proteomics. Mol Cell Biochem 418:71-80. 
10.1007/s11010-016-2734-X

34. Yu X, Zhang Y, Yang M, Guo J, Xu W, Gao J, Li Y, Tao L (2016) Cytotoxic effects of tebufenozide in vitro bioassays. Ecotoxicol Environ Saf 129:180-188. 10.1016/j.ecoenv.2016.03.025

35. Ma ZJ, Lu L, Yang JJ, Wang XX, Su G, Wang ZL, Chen GH, Sun HM, Wang MY, Yang Y (2018) Lariciresinol induces apoptosis in HepG2 cells via mitochondrial-mediated apoptosis pathway. Eur $\mathrm{J}$ Pharmacol 821:1-10. 10.1016/j.ejphar.2017.12.027

36. Simon HU, Haj-Yehia A, Levi-Schaffer F (2000) Role of reactive oxygen species (ROS) in apoptosis induction. Apoptosis 5:415-418. 10.1023/a:1009616228304

37. Hseu YC, Cho HJ, Gowrisankar YV, Thiyagarajan V, Chen XZ, Lin KY, Huang HC, Yang HL (2019) Kalantuboside $B$ induced apoptosis and cytoprotective autophagy in human melanoma A2058 cells: An in vitro and in vivo study. Free Radic Biol Med 143:397-411.

10.1016/j.freeradbiomed.2019.08.015

38. Liang QP, Xu TQ, Liu BL, Lei XP, Hambrook JR, Zhang DM, Zhou GX (2019) Sasanquasaponin III from Schima crenata Korth induces autophagy through Akt/mTOR/p70S6K pathway and promotes apoptosis in human melanoma A375 cells. Phytomedicine 58:152769. 10.1016/j.phymed.2018.11.029

39. Sui X, Chen R, Wang Z, Huang Z, Kong N, Zhang M, Han W, Lou F, Yang J, Zhang Q, Wang X, He C, Pan H (2013) Autophagy and chemotherapy resistance: a promising therapeutic target for cancer treatment. Cell Death Dis 4:e838. 10.1038/cddis.2013.350

40. Thiyagarajan V, Sivalingam KS, Viswanadha VP, Weng CF (2016) 16-hydroxy-cleroda-3,13-dien-16,15olide induced glioma cell autophagy via ROS generation and activation of p38 MAPK and ERK-1/2. Environ Toxicol Pharmacol 45:202-211. 10.1016/j.etap.2016.06.005

41. Dzwierzynski WW (2013) Managing malignant melanoma, Plast Reconstr Surg 132 446e-460e. 10.1097/PRS.0b013e31829ad411

42. Luke JJ, Flaherty KT, Ribas A, Long GV (2017) Targeted agents and immunotherapies: optimizing outcomes in melanoma. Nat Rev Clin Oncol 14:463-482. 10.1038/nrclinonc.2017.43

43. Ralli M, Botticelli A, Visconti IC, Angeletti D, Fiore M, Marchetti P, Lambiase A, de Vincentiis M, Greco A (2020) Immunotherapy in the Treatment of Metastatic Melanoma: Current Knowledge and Future Directions, J Immunol Res (2020) 9235638. 10.1155/2020/9235638

44. Wells JM, Gaggar A, Blalock JE (2015) MMP generated matrikines. Matrix Biol 44-46:122-129. 10.1016/j.matbio.2015.01.016

\section{Scheme}

Schemes 1 is available in the Supplemental Files Section.

\section{Figures}


A

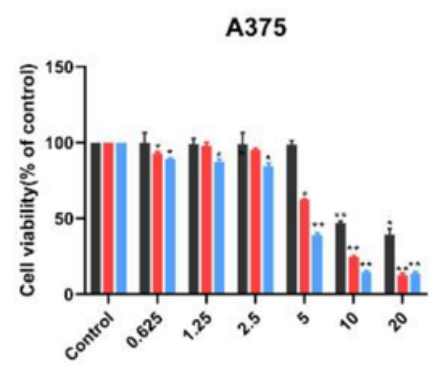

Concentration of SCZ0148 ( $\mu \mathrm{M})$

D

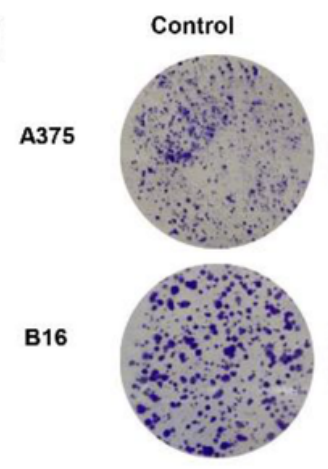

B

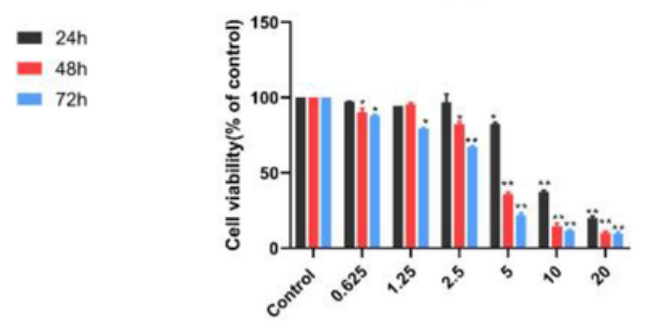

Concentration of SCZ0148 ( $\mu \mathrm{M})$
C

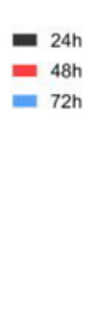

293T

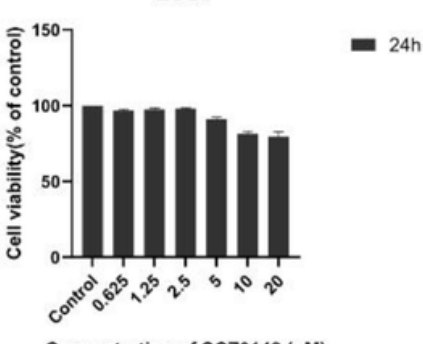

A375

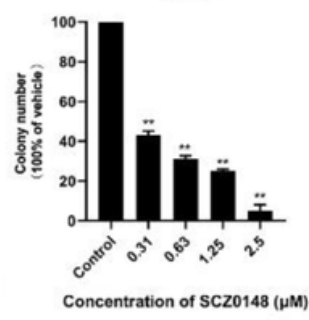

B16

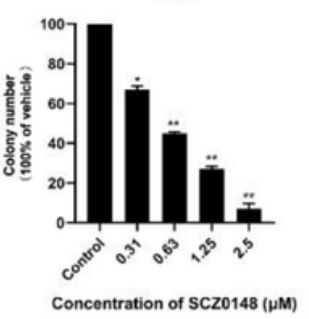

Figure 1

Anti-proliferative effects of SCZ0148. (A-C) A375, B16 and 293T cell lines were treated with various concentrations of SCZ0148 for $24 \mathrm{~h}, 48 \mathrm{~h}$ or $72 \mathrm{~h}$. Cell viability was detected by the MTT assay. (D) The effects of different concentrations of SCZ0148 on colony formation in A375 and B16 cells, the statistic results of colony formation assays showed as surviving colonies. All experiments were conducted in triplicate and each point represents the mean $\pm \mathrm{SD}\left({ }^{\star} P<0.05 ; * \star P<0.01\right.$ vs vehicle control). 


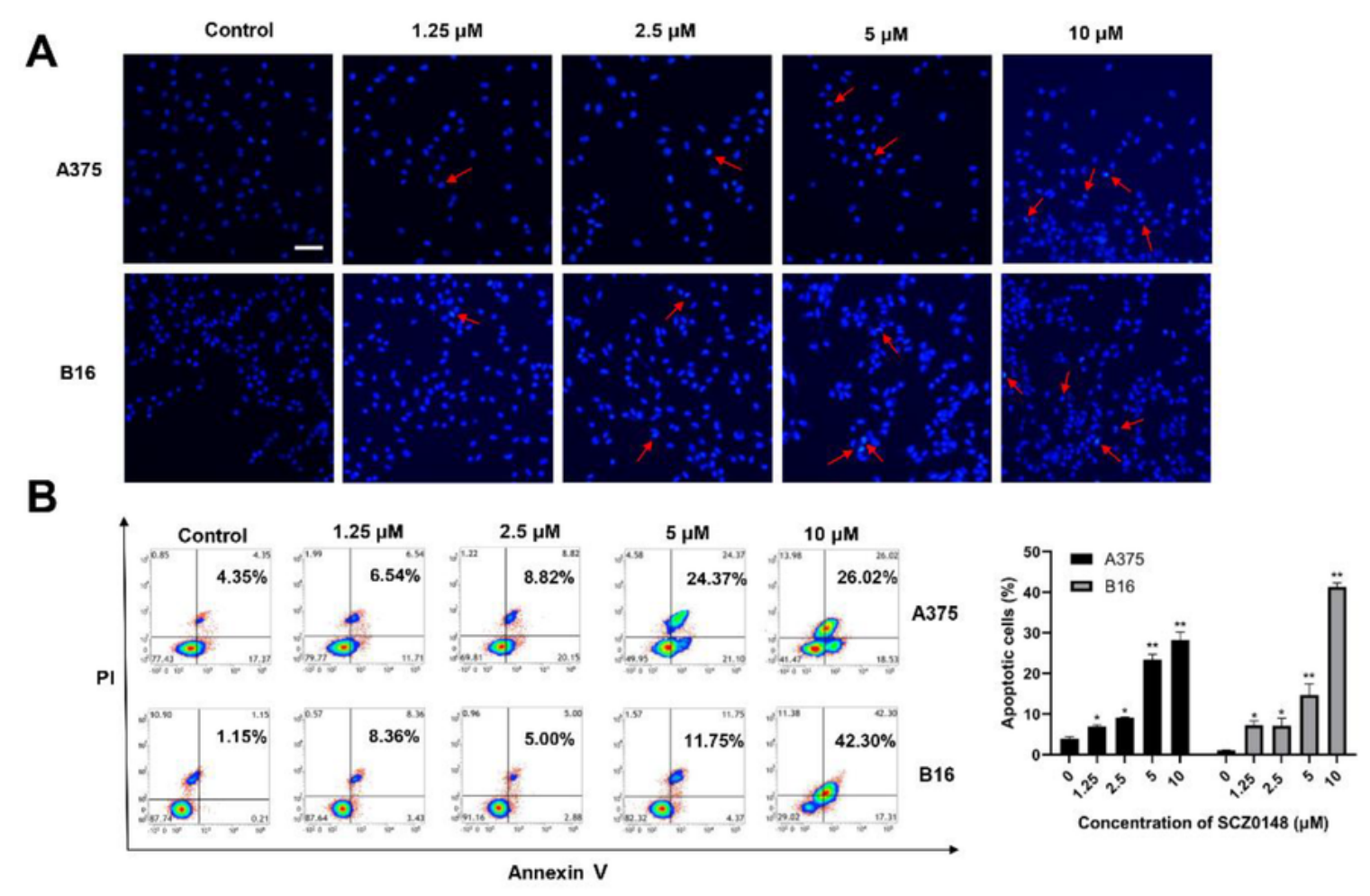

C

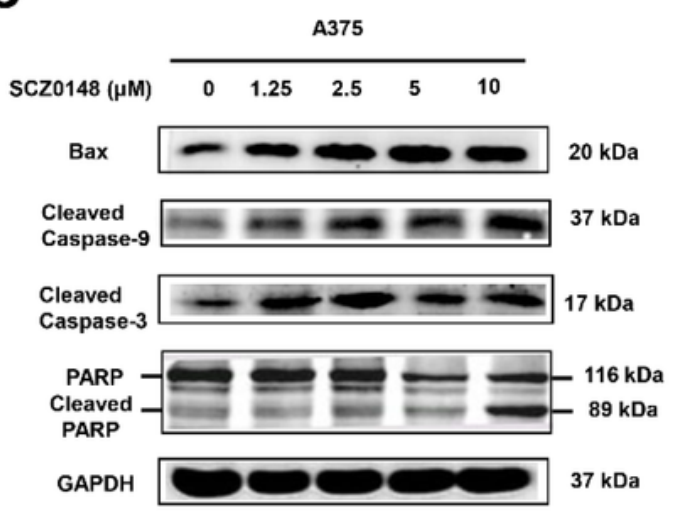

D
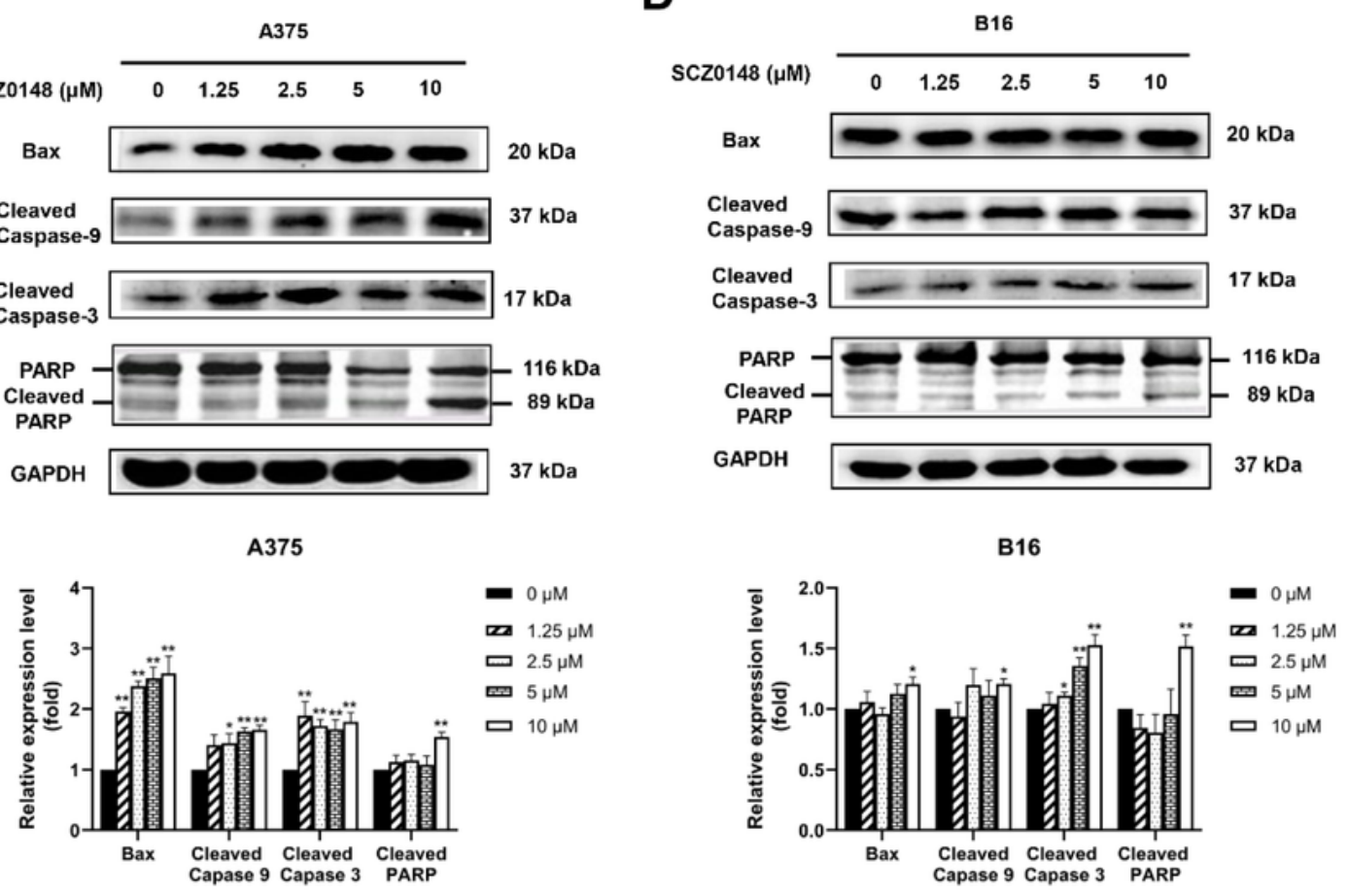

Figure 2

SCZ0148 induced apoptosis of A375 and B16 cells. (A) Fluorescence microscopic appearance of Hoechst 33342 stained A375 and B16 cells nuclei treated with graded concentration of SCZ0148 for $24 \mathrm{~h}$. The condensed nuclei and nuclear fragmentation are pointed out using the red arrow. (B) A375 and B16 cells were treated with a specified dose of SCZ0148 for $24 \mathrm{~h}$, and the apoptosis rate was counted. (C, D) SCZ0148 regulated the expressions of apoptosis-related proteins. The A375 and B16 cells were treated 
with SCZ0148 at gradient concentrations for $24 \mathrm{~h}$. Cell lysates were performed for analysis of the expression of Bax, cleaved caspase 9, cleaved caspase 3 and PARP by Western blot. GAPDH was set as the loading control. Data are the representative form triplicated experiments and represented by mean \pm SD. ${ }^{*} P<0.05 ; * \star P<0.01$ vs vehicle control.

A

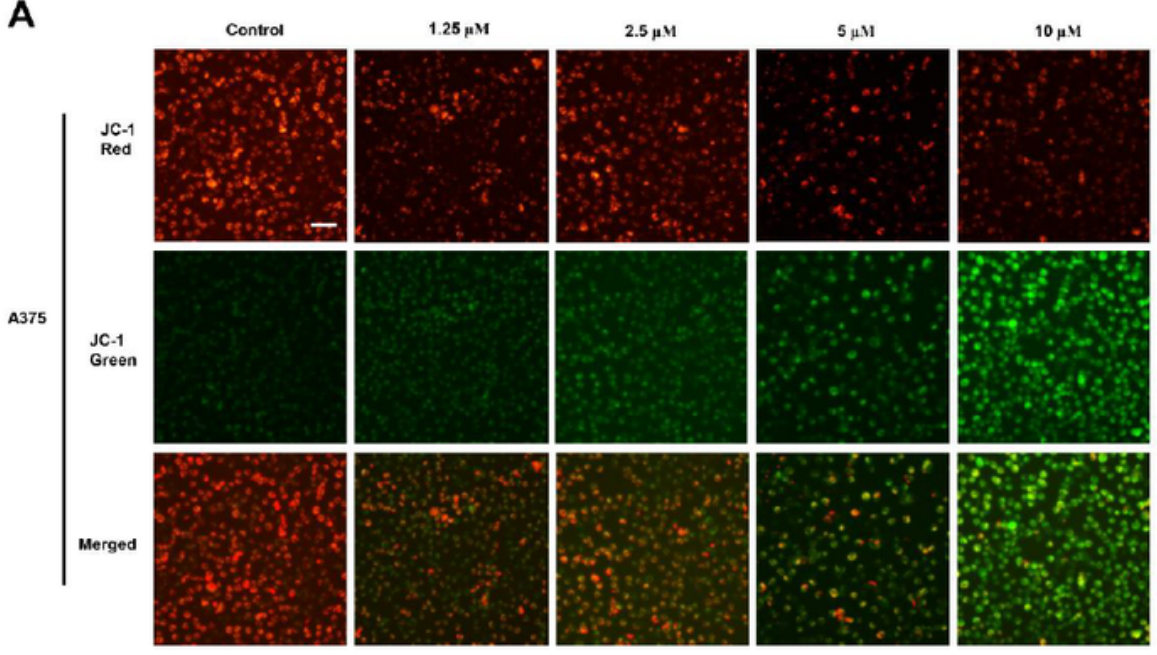

B
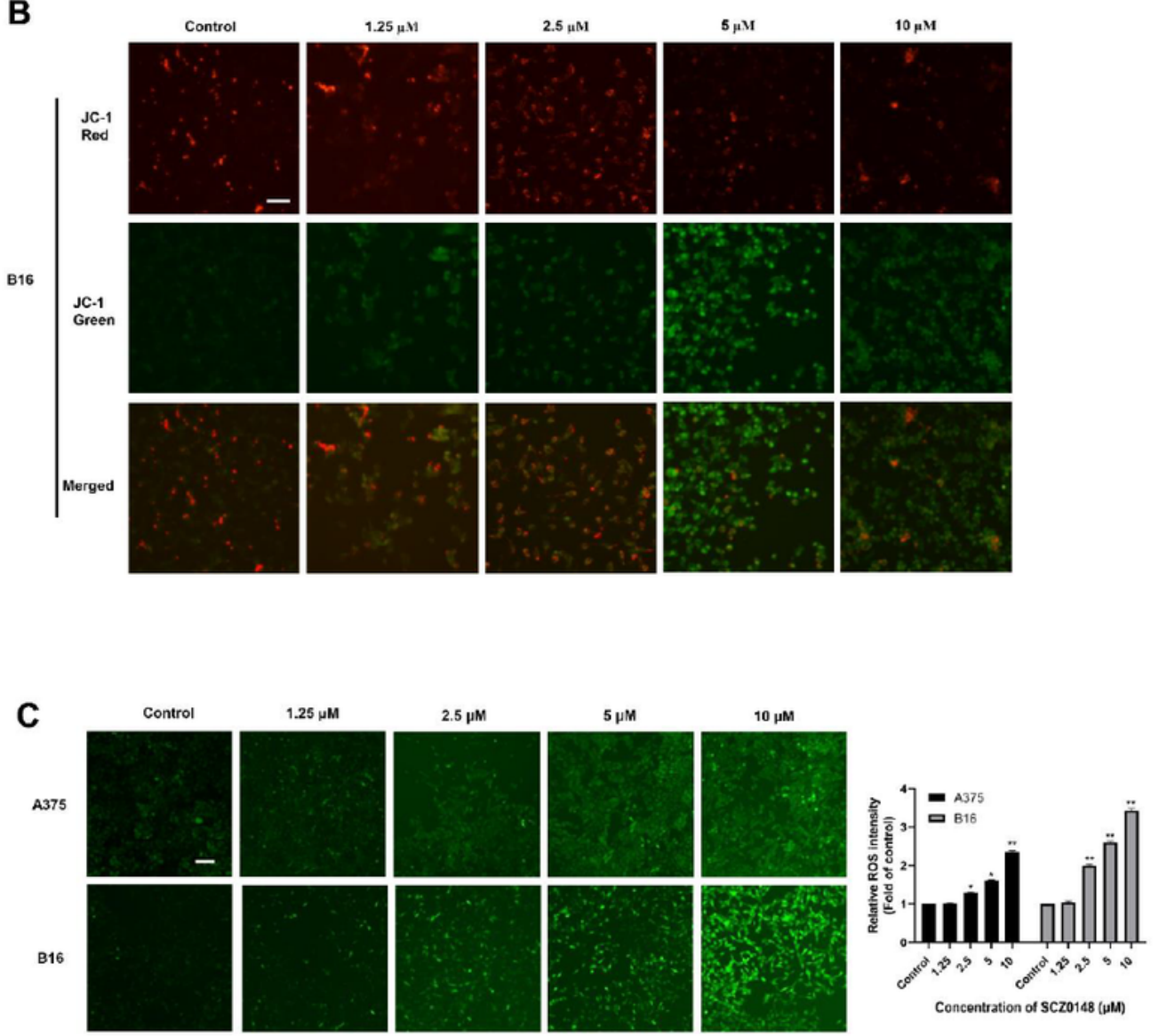

Figure 3 
The variation of mitochondrial membrane potential $(\Delta \psi \mathrm{m})$ and ROS levels in A375 and B16 cells. (A, B) SCZ0148 decreased mitochondrial membrane potential. A375 and B16 cells were exposed to gradient concentrations of SCZ0148 for $24 \mathrm{~h}$, then stained with JC-1 fluorescent dye and photographed by fluorescence microscope. The representative images and fluorescence quantitative statistical graphs are shown here respectively. (C) Effect of SCZ0148 on intracellular ROS. A375 and B16 cells were treated with different concentrations of SCZ0148 for 24 hours, and then the images were recorded by fluorescence microscope. Data are the representative form triplicated experiments and represented by mean \pm SD. ${ }^{\star} P<0.05 ; * \star P<0.01$ vs vehicle control.
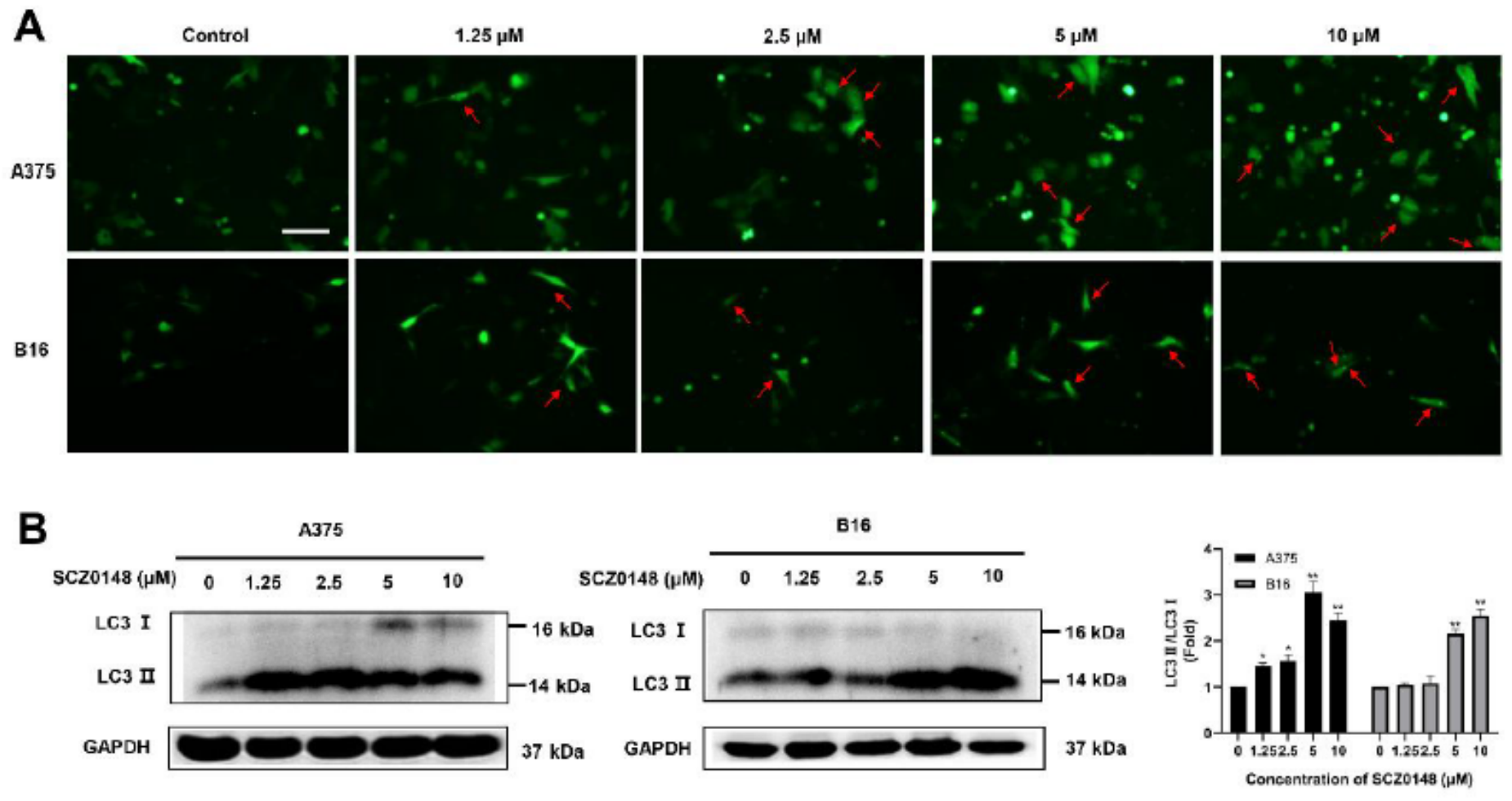

Figure 4

SCZ0148 induced autophagy in A375 and B16 cells. (A) The cells were transfected with GFP-LC3 plasmid for $12 \mathrm{~h}$, then treated with gradient concentrations of SCZ0148 for $24 \mathrm{~h}$, and the cells were observed by

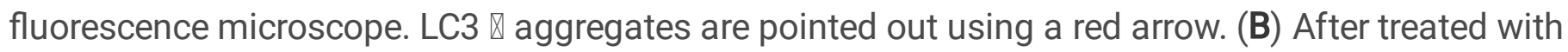
different concentrations of SCZ0148 for $24 \mathrm{~h}, \mathrm{LC} 3 \otimes / \otimes$ was analyzed by Western blot. GAPDH was used as the loading control. The data represent three separate experiments. Each point represents the mean \pm $\mathrm{SD}\left({ }^{\star} P<0.05 ;{ }^{\star \star} P<0.01\right.$ vs vehicle control). 


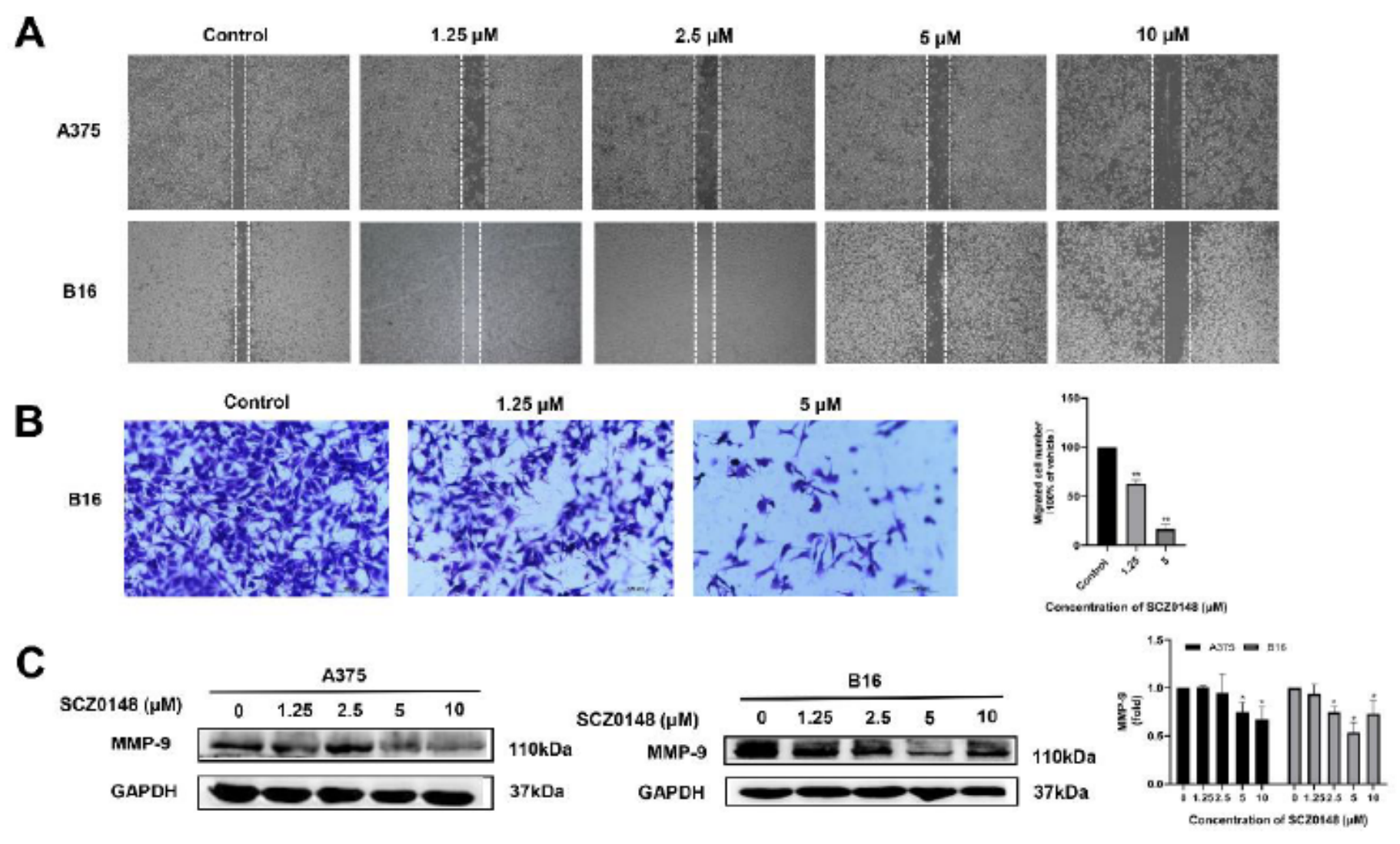

\section{Figure 5}

Inhibition of migration by SCZ0148 treated in A375 and B16 cells. (A) After treated with various concentrations of SCZ0148 (0-10 $\mu \mathrm{M})$ for $12 \mathrm{~h}$, the cells were photographed. (B) B16 cells were plated in the top chamber of the transwell with serum-free medium and treated with vehicle or different concentrations of nifuroxazide. After $24 \mathrm{~h}$, migrated cells were fixed, stained, photographed and quantified. (C) A375 and B16 were incubated with different concentrations of SCZ0148 for $12 \mathrm{~h}$. Western blot assay was performed to measure the expression of MMP-9. GAPDH served as a loading control and protein expression of MMP-9 was quantified and normalized against GAPDH protein expression. The data represent three separate experiments. Data are shown as mean $\pm \mathrm{SD}\left({ }^{\star} P<0.05 ;{ }^{\star \star} P<0.01\right.$ vs vehicle control (0 $\mu \mathrm{M}$ group)). 


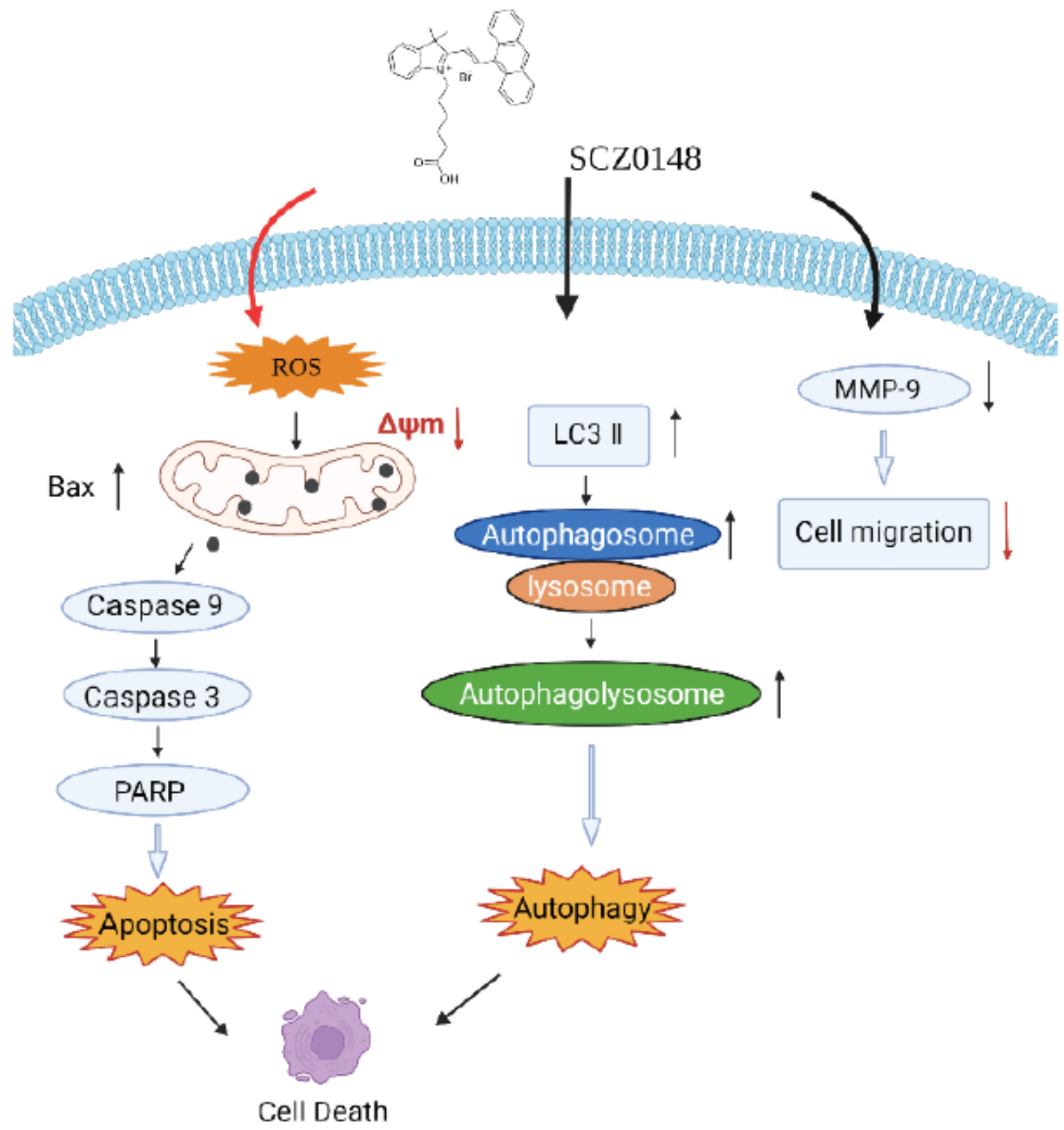

Figure 6

Anticancer mechanism of SCZ0148 against melanoma cells.

\section{Supplementary Files}

This is a list of supplementary files associated with this preprint. Click to download. 
- Scheme1.png

- Supplement.docx

Page 20/20 